\title{
APROXIMACIÓN A LA HISTORIA POLÍTICA DEL ALTO VALLE DEL EBRO DURANTE LOS SIGLOS V-VI D.C.
}

\author{
Santiago M. Castellanos*
}

RESUMEN: El presente trabajo consiste en una aproximación al conocimiento de los sucesos que jalonan la historia del Alto Ebro durante el último siglo del imperio romano (Pars Occidentis) y la época del reino de Tolosa y el primer siglo del de Toledo. El principal objetivo de este análisis consiste en introducir la problemática histórica que presenta esta zona, y que será objeto de nuevos estudios que aborden aspectos sociales, religiosos, económicos, a fin de avanzar en el estudio de Hispania durante la Antigüedad tardía.

ABSTRACT: This paper is an approximation to the knowledge of the events that mark out the history of High Ebro during the last century of roman empire (Pars Occidentis), and the period of kingdom of Tolosa and the first century of the kingdom of Toledo. The principal objective of this analysis is to introduce the historical problems that this zone offers, and that will be the target of new studies, and these will tackle social, religious, economic aspects, in order to advance in the study of Hispania during Late Antiquity.

Los acontecimientos que jalonan la historia política del Alto Ebro durante los siglos V-VI han de explicarse en el marco general de la evolución histórica de la sociedad tardorromana, particularmente en la Pars Occidentis. En este sentido, quisiéramos hacer notar la arbitrariedad de la denominación histórica que estamos empleando. Hablamos de "Hispania visigoda" o de "época visigoda" desde una pers-

\footnotetext{
* Universidad de La Rioja. Este trabajo ha contado con una beca FPI de la Fundación Cajarioja.
} 
pectiva restringida que ha conseguido autoridad historiográfica por el paso del tiempo. Sin embargo, el hecho de que los ejércitos imperiales apenas interviniesen ya a comienzos del siglo $\mathrm{V}$, junto a la posterior situación de una cobertura política visigoda, no pueden hacernos hablar de una "sociedad visigoda" en el puro sentido de la expresión. Aunque carecemos de datos seguros acerca del número de visigodos que se asentaron en la Península Ibérica a finales del siglo V y comienzos del VI, los índices cuantitativos son probablemente escasos. En estas consideraciones previas queremos basar los parámetros a partir de los cuales deben entenderse los hitos "evenemenciales" de la problemática histórica que tratamos de abordar.

En el caso hispano, la presencia y, sobre todo, la actividad del ejército imperial romano parece reducirse a la mínima expresión ya en los comienzos del siglo $\mathrm{V}^{1}$. Ante la rebelión/usurpación de Constantino, las tropas que debiéramos suponer -si hacemos caso al catálogo conocido como Notitia Dignitatum²- asentadas en el norte peninsular, en realidad no aparecen. El debate sobre este problema ha originado numerosos trabajos que resultaría prolijo recoger aquí3. Han de ser los parientes de Honorio quienes organicen un ejército privado con sus dependientes (Oros., VII, 40, 5-6; Soz., IX, 11; Zos., VI, 4, 2-4). El episodio de Dídimo y Veriniano refleja la incapacidad militar del imperio romano para hacer frente en Hispania, de manera oficial, a una usurpación de notable trascendencia ${ }^{4}$. En todo caso, los ejércitos al mando de Constancio sí terminan con el usurpador en Arlés en el año 411 (Oros., VII, 42, 3).

1. En todo caso, a partir de la primera década del siglo $\mathrm{V}$, la verdadera trascendencia viene protagonizada por los ejércitos privados, cfr. SANZ, 1986: 257.

2. Sobre los problemas que presenta esta fuente, ver CLEMENTE, 1968; ARCE, 1980; JONES, 1986: 1417-1450.

3. A nuestro juicio, la Notitia es un documento que por sí mismo no aporta datos vívidos sobre la presencia militar imperial en Hispania. El hecho de que se mencionen una serie de tropas comitatenses y limitanei apenas aparece contrastado en las demás fuentes. Sí puede resultar interesante la epístola del emperador Honorio a los soldados de Hispania (véase la edición de SIVAN, 1985: 274; también han analizado esta fuente DEMOUGEOT, 1956; JONES, 1964:1106). Más allá de la problemática acerca del Saviniano que aparece en el documento, nos interesa aquí la alusión a los movimientos de diversarum gentium barbarorum. Pese a la práctica imposibilidad de fechar con precisión la carta, tanto la datación en Honorio como la alusión a bárbaros inducen a pensar en el 409 como término post quem. De seguir la hipótesis de Sivan, según la cual la carta no se dirige exclusivamente a los auxilia palatina (como pensaba JONES, 1964:1106), sino tanto a éstos como a las legiones comitatenses, tendríamos que el ejército imperial en Hispania por estas fechas tan sólo estaba compuesto por dos legiones comitatentes y nueve auxilia palatina, esto es, un total de unos 6.500 soldados. Esto, evidentemente, supone un descenso en comparación con las cifras de la Notitia, que habla de 16 cuerpos (5+11), unos 10.500 hombres. Más allá de estas consideraciones generales, la epístola de Honorio atestigua la presencia en el Norte de Hispania (en Pamplona concretamente) de ejércitos imperiales, con una misión que se nos escapa, pero que probablemente tendría mucho que ver con movimientos de bárbaros. En todo caso, de las primeras palabras del documento se desprende que la misión de Saviniano es coyuntural y que ha llegado a Hispania a causa del problema: Incipit sacra Honorii imperatoris quam de Roma detulit militia urbis Pampilonensis cum Saviniano patricio qui <eo >dem tempore, †erede† praelatus, in Spaniam profectus est ob infestatione diversarum gentium barbarorum [...].

4. Estos episodios han sido tratados con profundidad, entre otros, en los trabajos de STEVENS, 1957: 318 ss; STROHEKER, 1965: 54 ss, esp. 70 ss; MATTHEWS, 1975: 307 ss; ZECCHINI, 1983: 101-113; ARCE, 1986: 24 ss; ID., 1988: 68-121. 
Más claro resulta, en este contexto, el dato de la entrada de suevos, vándalos y alanos en 409. Más claro por cuanto no tenemos noticias de una decidida oposición militar imperial. ${ }^{5}$. Ha de ser un foedus de 416, entre Constancio y Walia, el que impulse la aniquilación de una parte de los vándalos silingos y de los grupos alanos (Oros., VII, 43, 13; Hydat., 63, 67-68). Como consecuencia de este acuerdo y la acción militar visigoda, éstos reciben acomodo en las Galias, formando un reino con capital en Tolosa.

La Península Ibérica asiste, durante el siglo $\mathrm{V}$, a un fenómeno que perdura durante gran parte de la Antigüedad tardía. Se trata de la profundización en el control del poder sobre la esfera local, en relación con el desarrollo del patrocinio. El reino suevo, en el NO., parece no crear unas estructuras estatales muy profundas, adecuando los esquemas organizativos anteriores. Ello se encuentra en relación con la presencia de una aristocracia realmente poderosa que acentúa su poder en el ámbito local. Incluso los monasterios que se instalan, en buena proporción, se explican desde esta perspectiva ${ }^{6}$. Los recientes trabajos de Fernández Ardanaz han puesto de manifiesto la trascendencia que el desarrollo del cristianismo juega en la conformación de las sociedades del Norte Peninsular durante la Antigüedad tardía y la Alta Edad Media y, junto a ello, la importancia que presenta la articulación local y tribal del territorio: en este sentido, uno de los elementos claves viene definido por la presencia de villae con oratorios e iglesias, mecanismo básico para entender la dinámica histórica en este ámbito?.

La única provincia que nominalmente seguía formando parte del imperio romano, la Tarraconense -de la que el Alto Ebro forma parte-, experimenta unos procesos en buena parte enmarcables en la evolución histórica del territorio imperial occidental. Nos estamos refiriendo a la noticia concreta de los episodios bagáudicos.

En 441 Asturio, dux utriusque militiae, es enviado a la Tarraconense para enfrentarse a los bagaudas (Hydat., 125). Dos años después es Merobaudes quien breui tempore potestatis suae Aracellitanorum frangit insolentiam Bacaudarum (Hydat., 128). Un grupo de bagaudas (se cita a un tal Basilio como posible caudillo) reunidos en la iglesia de Tarazona, acaban con el obispo León y con los foederati (Hydat., 141). Se alude incluso a una colaboración entre los bagaudas de Basilio y los suevos de Requiario, fruto de la cual son saqueadas las zonas de Zaragoza y Lérida (Hydat., 142). En 453 Frederico, hermano del monarca Teodorico, vence a los bagaudas de la Tarraconense ex auctoritate romana (Hydat., 158).

Más allá de la interpretación "nacionalista" o "étnica" de estos sucesos, la bagauda gala e hispana pone de relieve el resentimiento de unos grupos de población hacia

5. Si exceptuamos la referencia de la epístola de Honorio a la que nos hemos referido arriba (supra, n. 3).

6. Para estos análisis, vid. DÍAZ MARTÍNEZ, 1986; Id., 1986-87; Id., 1990. La importancia del horizonte local durante la Spätantike hispana ha sido bien rastreada por NELSON, 1970; Más recientemente, COLLINS, 1986. Ello puede relacionarse también con el progreso de la idea del individuo, como, para los últimos años del imperio, ha dicho PARADISI, 1978: 67, "La separazione dell'uomo dallo Stato, che fu una catastrofe per la civiltà antica, favorí il sorgere di una nuova paideia [...]".

7. FERNÁNDEZ ARDANAZ, 1992; Id., 1994. 
el dominio efectivo de los grandes propietarios ${ }^{8}$. El hecho de que hubiese contingentes vascones entre los bagaudas no implica que estemos ante un movimiento étnico. Las fuentes no sólo hispanas, sino también galas, inducen a caracterizarlo básicamente como una parte de las manifestaciones de rechazo a la situación deplorable en que muchos grupos se encontraban'. El relato de Salviano de Marsella, tantas veces citado, resulta a nuestro juicio muy ilustrativo en este sentido: ante la persecutio publica (fundamentalmente fiscal), la solución para muchos no es otra que el refugio entre godos y bagaudas (De Gub. Dei V, 21-22).

En definitiva, a mediados del siglo $\mathrm{V}$ resulta patente la progresiva participación de los visigodos como brazo armado del imperio, primero, y como sustituto de éste en el control político de Hispania, después ${ }^{10}$. Ya con Ataúlfo, el sucesor de Alarico, casado con Gala Placidia, se advierte una teoría política que apunta hacia unos matices pragmáticos: en un comentario (Oros. VII, 43, 5) ${ }^{11}$ afirma Ataúlfo que en un primer momento había decidido acabar con el imperio, pero, vistas las circunstancias, prefería apoyarlo. No obstante, el reino visigodo verá limitado su poder efectivo en un juego de equilibrio con el control que las aristocracias ejercen en el ámbito de lo local: hasta la época de Eurico el reino tolosano no afrontará definitivamente una administración de tipo provincial por encima del ámbito de las civitates $^{12}$. En todo caso, se pretende aquí únicamente presentar los principales hechos políticos y militares que jalonan el proceso de la implantación visigoda como estado en gran parte de Hispania.

Y los hechos experimentan, en torno a 472-473, un momento crucial en la Tarraconense: la provincia pasa en la primera mitad de la década de los setenta al poder visigodo (Jordanes, Get., XLVII, 244; Isid., HG, 34). La Chronica Gallica menciona la doble expedición que acometió la toma de la provincia a partir de los Pirineos, por sus extremos occidental y oriental. Nos interesa aquí más la operación por la zona oeste, puesto que se toman plazas próximas al Alto Ebro; es el caso de

8. La posición de esta misma aristocracia del Valle del Ebro viene reafirmada por la documentación desprendida de la carta de honorati y possessores de esta zona al papa Hilario en relación con las ordenaciones irregulares que efectuaba Silvano, obispo de Calagurris. Sobre este asunto, ver entre otros los trabajos de ESCRIBANO, 1984; LARRAÑAGA, 1989; CASTELLANOS, 1995.

9. Se pueden encontrar distintas posturas en SÁNCHEZ-ALBORNOZ, 1979: 343-352; BARBERO, VIGIL, 1974: 46-47; THOMPSON, 1981; MUSSET, 1982: 159; BRAVO, 1983; Id., 1985; REMONDON, 1984: 136; COLLINS, 1989: 97.

10. Se ha valorado a la luz de las fuentes la posibilidad de una verdadera sintonía entre los grupos de poder local -tanto laico como eclesiástico- del Valle del Ebro y los elementos visigodos que actúan en la zona: cfr. ESPINOSA, 1991.

11. Orosio afirma explícitamente en este pasaje que el comentario de Ataúlfo lo conoce porque lo ha escuchado a un ex-combatiente narbonense de Teodosio, que a su vez lo relataba a Jerónimo en Belén. Al parecer este informador frecuentaba los círculos de Ataúlfo, siempre según el testimonio de Orosio. De ser esto cierto, el testimonio presenta interés por su condición de noticia coetánea para el conocimiento de la praxis política de los visigodos en los momentos previos a la conformación del reino de Tolosa. El contexto de esta noticia ha sido estudiado recientemente por ROUSSEAU, 1992.

12 WOLFRAM, 1990: 215. 
Pamplona y Zaragoza (DXI, 652) ${ }^{13}$. Según Isidoro $(H G, 34)^{14}$, los visigodos encontrarían cierta resistencia en la nobilitas provincial ${ }^{15}$.

Los acontecimientos se agolpan a finales de siglo. Parece que un tal Burdunelo "asume la tiranía" en Hispania en el año 496 (Chron. Caesar. ad a. 496); esta misma fuente afirma que, al año siguiente, Gothi intra Hispanias sedes acceperunt y que el citado Burdunelo es llevado a Tolosa, donde es ajusticiado (Chron. Caesar. ad a. 497). El año anterior a la derrota de Vouillé otro tirano, Pedro, es ejecutado en Zaragoza (Chron. Caesar. ad a. 506) ${ }^{16}$. Resulta muy probable el traslado de población visigoda a finales de siglo, antes de la derrota de Vouillé, como atestigua la Chronica. El problema radica en la valoración de la entrada de contingentes visigodos, tanto en lo que afecta a su número como en lo referente a su destino. El primero de los problemas halla un consenso general, en lo que se ciñe a la escasa proporción de visigodos que se asientan en Hispania en comparación con la población preexistente. En el segundo de los puntos el consenso es mucho menos claro.

Podemos sintetizar el problema en dos bloques teóricos. Por un lado, aquéllos que defienden la situación preferente de los visigodos en la Meseta, en lo que se ha venido denominando "área de las necrópolis", que arqueológicamente parece presentar dos fases. Una primera etapa correspondería al período tardorromano (básicamente, siglos IV-V; se trata de las llamadas "necrópolis del Duero") y una segunda que se superpone a la anterior y que presenta cronología visigoda. Por otra parte, se ha propuesto una ubicación de los asentamientos visigodos en los principales enclaves urbanos de la Tarraconense. No es éste lugar para entrar con profundidad en el debate historiográfico ${ }^{17}$.

Se ha de notar, en cualquier caso, que los conocimientos arqueológicos correspondientes al período de la Spätantike hispana se encuentran aún bastante difusos. Hecha esta consideración, el problema parece hoy poco práctico, por cuanto puede resultar complicado definir conceptos tales como "asentamiento visigodo" sin sobrepasar el calificativo meramente cronológico. Probablemente ha de ser un enfoque global el que deba presidir la aproximación al conocimiento arqueológico de la Antigüedad Tardía en Hispania, del mismo modo que el análisis histórico se aborda hoy sin arquetipos étnicos previos como principal premisa.

Como balance a los sucesos más significativos que acontecen durante el siglo $\mathrm{V}$, puede afirmarse que el Valle del Ebro experimenta un trasiego de tropas aprehensi-

13 THOMPSON, 1978: 6-7. Chron. Gall., DXI, 651, Gauterit comes Gothorum Hispanias per Pampilonem, Caesaraugustam, et vicinas urbes obtinuit.

14 Inde Pampilonam et Caesaraugustam misso exercitu capit superioremque Spaniam in potestatem suam mittit. Tarraconensis etiam prouinciae nobilitatem, quae ei repugnauerat, exercitus inruptione euertit.

15 En cualquier caso, se trataría de una de las pocas veces en que las aristocracias occidentales se oponen con las armas a los invasores bárbaros, cfr. THOMPSON, 1978: 6.

16 La valoración del significado de tyrannus en éstos y otros episodios de la sociedad hispanovisigoda ha sido contextualizada por ORLANDIS, 1962: 13-42.

17 Vid. REINHART, 1945; PALOL, 1966; CABALLERO ZOREDA, 1984: 441; GARCÍA MORENO, 1987: 332. Una alternativa a la tesis tradicional en DOMÍNGUEZ MONEDERO, 1986a; Id., 1986 b. 
ble en las fuentes: tanto los episodios bagáudicos y la respuesta imperial como las acciones que llevan a Eurico a controlar la Tarraconense, última provincia en posesión imperial, son buena muestra de ello. Ello sin olvidar las incursiones de Requiario en la Tarraconense $\mathrm{e}^{18}$ y la respuesta imperial por medio de los foederati godos de Teodorico, que vence a los suevos en 455 (Hydat., 172-173; Isid, $H G, 31,87$ ). Por cierto que Jordanes, al recordar este suceso, se refiere a la zona que lindaba orientalmente con el reino suevo y la denomina Austrogonia (Get. XLIV, 230), en referencia probablemente anacrónica al solar de los autrigones, uno de los pueblos prerromanos situados en torno al Alto Ebro ${ }^{19}$. Este escenario continuará durante las etapas siguientes como foco de las manifestaciones geopolíticas.

La dinámica a la que estamos haciendo referencia puede haber jugado un pape1 destacado en la configuración del hábitat tardoantiguo en el Alto Valle del Ebro: junto a núcleos de tipo urbano como Calahorra, hay que tener muy en cuenta el poblamiento serrano en castros (tema que para esta zona merece un estudio pormenorizado) y, desde luego, la habitación en cuevas. La profusión de éstas en toda la zona no puede ser explicada únicamente desde la perspectiva del eremitismo ${ }^{20}$. Sin duda alguna, este fenómeno se encuentra presente en el Alto Ebro -el caso de Emiliano, en el siglo VI, es paradigmático-, pero la abundancia del hábitat rupestre hace pensar que, junto a la presencia de eremitas, una parte considerable de la población habita en estos momentos en cuevas y ello, como decimos, puede relacionarse con los procesos que estamos analizando ${ }^{21}$.

El siglo VI comienza con la derrota de los ejércitos de Alarico II frente a los francos en Vouillé22. A partir de este momento, y promocionado por la ayuda prestada de cara a la conservación visigoda de la franja costera de la Provenza y Narbonense, el ostrogodo Teodorico va a supervisar las acciones del pueblo visigodo ${ }^{23}$, iniciando una etapa denominada por R. d'Abadal ${ }^{24}$ intermedio ostrogodo .

Lo interesante para nosotros es observar que se produce, si se considera plausible la paulatina penetración de elementos visigodos en la Península durante el período

18 HYDAT., 140, 142; ISID., $H G, 87$ : el monarca suevo, después de casarse con la hija de Teodorico I, ataca Vasconia en febrero de 449 , y en el mes de julio, al ir al encuentro de su suegro, devasta la zona de Zaragoza, en alianza con los bagaudas de Basilio.

19. Sobre los autrigones, vid. SOLANA, 1978.

20. Tema léase en MONREAL JIMENO, 1989.

21. La hipótesis ya fue apuntada por GONZÁLEZ BLANCO, ESPINOSA RUIZ, SÁENZ GONZÁLEZ, 1979.

22. En este sentido, el lacónico documento caesaraugustano es muy efectista: His diebus pugna Gotthorum et Francorum Boglada facta. Alaricus rex in proelio a Francis interfectus est: regnum Tolosanum destructum est (Chron. Caesar., ad. a. 507).

23. En cierto modo, ello era una continuación de la ayuda prestada por Alarico II a Teodorico cuando éste se hallaba sitiado en Pavía por Odoacro en 490. Por otro lado, dos hijos de Alarico (Gesaleico y Amalarico) se presentaban como candidatos al trono; Amalarico, precisamente, era hijo del monarca fallecido $y$ Tiudegoto, hija del propio Teodorico, con lo que el rey ostrogodo mantenía una razón y excusa clara a fin de controlar la situación política del reino visigodo, cfr. GARCÍA IGLESIAS, 1975: 94.

24. ABADAL, 1960: 54ss. Ver además GARCÍA IGLESIAS, 1975; para la política exterior de Teodorico puede tomarse un reciente punto de partida en MOORHEAD, 1992. 
496-507, un nuevo trasiego de gentes a través del Alto Ebro. El empleo de la vía Aquitana es muy probable, con mansiones tales como Veleia, Vindeleia, Deobriga, situadas de lleno en la zona de nuestro estudio ${ }^{25}$. A partir de estos instantes podríamos plantearnos un tema que la historiografía ha considerado vital. Se trata de los sistemas de ocupación del territorio por parte de los visigodos. El problema excede los límites temáticos de este trabajo ${ }^{26}$, que únicamente pretende ilustrar una serie de sucesos políticos y militares como primer eslabón para la comprensión global de los procesos históricos explicables en el Valle del Ebro durante los siglos V-VII.

Tras el período que se ha venido en llamar "intermedio ostrogodo", la monarquía visigoda atraviesa momentos difíciles acompañados de luchas intestinas. La amenaza exterior se ve refrendada por la expedición franca de mediados de siglo ${ }^{27}$. Childeberto centra su acción en el Valle Medio del Ebro, sitiando Zaragoza. El paso de los ejércitos francos se produce por Pamplona, y el asedio a Zaragoza se prolonga durante cuarenta y nueve días. Teudis encarga las tareas de más directa refriega militar a su general Teudiselo, que probablemente consiguió cortar a los francos la retirada por los Pirineos; se acordó un plazo de una jornada para que el ejército invasor abandonara la Península ${ }^{28}$. Por otra parte, las pugnas intestinas constituyen otro factor a tener en cuenta y, en este sentido, resulta emblemática la lucha entre las facciones de Agila y Atanagildo, que propician la presencia bizantina en la Península como consecuencia del apoyo a uno de los bandos.

Junto a ello se han de tener en cuenta las fuerzas centrífugas reflejadas en la hegemonía de las aristocracias locales. Ello sin olvidar la perduración del reino suevo del NO. Leovigildo va a tratar de hacer frente a todas estas fuerzas, y quizás desde esta orientación deba ser entendida su llamada "política religiosa"29. Las investigaciones de las últimas dos décadas hacen ver el reinado de Leovigildo como el intento por 1levar a la práctica una mayor implantación territorial de la monarquía visigoda ${ }^{30}$. Más que el enfrentamiento religioso entre católicos y arrianos, se plantea el problema en claves de control político, social y económico, a los que, evidentemente, resultaba inherente el religioso. Así, por ejemplo, la pugna entre Masona y Leovigildo no parece responder, de manera exclusiva, a una cuestión meramente teológica. Más bien estamos ante el conflicto por el poder en una de las principales ciudades hispanas. Masona y su significado histórico responden a los caracteres de una buena parte del

25. La relación de mansiones en el Itinerarium Antonini Augusti, 454; también en el Ravenate , IV, 45, 18. 26. Sobre tan debatido asunto, vid. GARCÍA GALLO, 1940-41; DOPSCH, 1948; GOFFART, 1980.

27. Chr.Caesar., ad a. 541, Hoc anno Francorum reges numero V per Pampelonam Hispanias ingressi Caesaraugustam venerunt, qua obsessa per quadraginta novem dies omnem fere Tarraconensem provinciam depopulatione attriverunt; ISID., HG, 41 Eo regnante, dum Francorum reges cum infinitis copiis in Spanias. conuenissent et Tarraconensem prouinciam bello depopularent, Gothi duce Theudisclo obicibus Spaniae interclusis Francorum exercitum multa cum admiratione uictoriae prostrauerunt.

28. Una reconstrucción de los acontecimientos en BRËNS, 1955-56: 59ss.

29. Sobre la política religiosa de Leovigildo es clásico el trabajo de SCHÄFERDIEK, 1967: 157 ss.

30. En el aspecto territorial y la pugna entre el centralismo y los poderes locales (bien ejemplificados en el caso emeritense) ha incidido especialmente COLLINS, 1980. 
episcopado tardoantiguo, respaldado por un imponente patrimonio diocesano, en este caso parcialmente heredado de sus antecesores Paulo y Fidel (recordemos la donación por un aristócrata lusitano en agradecimiento a la cesárea que Paulo efectúa a su esposa). Junto a este patrimonio, Masona cuenta con su carisma personal y, sobre todo, con la capitalización que ejerce del culto de santa Eulalia, similar al que lleva a cabo Gregorio con san Martín en Tours. Todos estos elementos conferían a Masona una gran autoridad en un enclave como el emeritense. Obviamente, esto entraba en conflicto con las aspiraciones de Leovigildo. El caso de Masona es extrapolable a otros sucesos del mismo reinado (como la lucha con Hermegildo) y de la sociedad hispanovisigoda, en general.

Por tanto, el contexto de la campaña en Cantabria (574) entronca con diferentes procesos que afectaban, de manera global, a la evolución política y socioeconómica de la Hispania tardoantigua. Las fuentes que nos informan acerca de la campaña del año 574 son tres: Juan de Bíclaro, Isidoro y Braulio de Zaragoza. Leovigildo entra en Cantabria, acaba con unos pervasores y ocupa la zona $^{31}$. Las escuetas referencias plantean serios problemas de interpretación. Pueden ser subrayados los siguientes: la localización geográfica del territorio conquistado por Leovigildo, la identidad de los pervasores, y la intensidad de dicha ocupación con un posible refrendo administrativo.

El Biclarense alude a la toma de Amaya como uno de los hitos principales de la conquista de Cantabria. La situación del enclave de Amaya parece centrarse en el yacimiento de Peña Amaya, al norte de la actual provincia de Burgos, que presenta registro arqueológico al menos desde la Edad del Bronce, ofreciendo cerámica pintada de cronología visigoda ${ }^{32}$. Junto a esto, existen referencias en la VSE a las relacio-

31 IOH. ABB. BICL., a. 574, His diebus Leovegildus rex Cantabriam ingressus provinciae pervasores interficit, Amaiam occupat, opes eorum pervadit et provinciam in suam revocat dicionem. Además, ISID., $H G, 49$, Cantabrum namque iste obtinuit. VSE, XXVI, 33, Eodem igitur anno, quadragesimae diebus reuelatur ei etiam excidium Cantabriae [...].

32. Para la identificación de Amaia con Peña Amaya (Burgos), ver ALBERTINI, 1923: 121, n. 9; STROHEKER, 1965: 82; GONZÁLEZ ECHEGARAY, 1966: 85, “Otras cinco millas al sur de Vellica se cita finalmente a la estación de Amaia. Esta ciudad no aparece en otras fuentes romanas, pero es ampliamente citada como cántabra en las medievales. Aún se conservan las ruinas de la ciudad sobre el monte llamado Peña Amaya. Allí se ha recogido abundante material arqueológico romano, aunque es fácil que la propia estación que cita el itinerario estuviera en el llano, no en el monte, y cercana al Pisuerga, por donde pasaba la vía romana", situando a su vez Vellica en Monte Cildá (acerca de este yacimiento, véase GARCÍA GUINEA, GONZÁLEZ ECHEGARAY, SAN MIGUEL RUIZ, 1966: esp. 23ss). El itinerario al que se refiere González Echegaray es el llamado Itinerario de Barro, hallado cerca de Cangas de Onís (para los problemas de este documento, y su datación, vid. DIEGO SANTOS, 1959: 246-249). Los topónimos de este documento y las millas de distancia no dejan lugar a dudas acerca de la localización de Amaia al sur de la zona cántabra:[Via]L[egione]VIGeminaadPortumBle[n]dium/Rha[m]a...VIImilias/Amaia...XVIIIm./Villegia...Vm .LegioI[V]...V/Octaviolca...V/Iuliobriga...X/Aracillum...V/P[or] tus Blen[dium] / [C. Lep (idus) $M$ (filius)] II vir (lectura de GONZÁLEZ ECHEGARAY, 1966: 39). Desde el punto de vista arqueológico, Peña Amaya es un castro que presenta ocupación desde la Edad del Bronce, arrojando abundante cerámica pintada de época visigoda, cfr. ABASOLO, 1978: 51 ss. En la misma línea de situar Amaia en Peña Amaya, ver BARBERO, VIGIL, 1974: 88; GARCÍA MORENO, 1974: 139-140; GARCÍA MERINO, 1975: 225; BESGA MARROQUÍN, 1983: 25; TOVAR, 1989: c-343, 345. Junto a esto, anotemos que se documenta en Peña Amaya un tremis de Recaredo con leyenda RECCAREDVS REX, cfr. BARRAL, 1976: 178. 
nes entre el oratorio emilianense y algunos personajes de la zona de Amaya que acuden al santo en busca de sanación ${ }^{33}$. El propio Braulio, ante el exorcismo efectuado por Emiliano a Nepociano y Proseria comenta que "no hay nadie entre los cántabros que no lo haya conocido bien de vista bien de oídas"34. El concepto geográfico de "Cantabria" durante la época tardorrepublicana y altoimperial comprendía no sólo la actual C. A. de Cantabria, sino también los sectores septentrionales de las actuales provincias de Palencia y Burgos ${ }^{35}$. Esto no cambia durante la Spätantike; en todo caso, se amplía la extensión de esta noción geográfica. Braulio, que escribe desde Zaragoza c. 636, tiene in mente que los sucesos que narra acontecen en zona de cántabros, y de ahí la expresión de VSE XV, 22.

Quizás el debate historiográfico se ha visto acentuado y ha conducido a posturas extremistas debido a la introducción de una variante en la interpretación de los hechos. Dicha variante viene definida por la teoría según la cual la Cantabria atacada por Leovigildo es el yacimiento de Monte Cantabria, sito junto a la actual ciudad de Logroño ${ }^{36}$. En ningún momento Juan de Bíclaro, Isidoro o Braulio hablan de Cantabria como una ciudad. Un texto conocido como la nota de Cantabria del códice emilianense 39 (=nota 39), que puede ser datado en el siglo XI, aporta una variable que engrosa el debate historiográfico. La nota 39 alude a la campaña de Leovigildo, tomando como referencia las fuentes que ya se han mencionado. Además, reseña la rebelión de Paulo y la derrota de éste ante el rey Wamba, que también se había enfrentado a los vascones ${ }^{37}$. Finalmente, la nota 39 especifica que "Cantabria se localiza en el monte Iggeto, cerca de la fuente del Ebro. Y la destruyó el rey Leovigildo; este rey fue hereje" "38. El monje encargạdo de realizar estas anotaciones se ha preocupado de recordar que la Cantabria de la que está hablando es la de las fuentes del Ebro y no otra. La localización en el Alto Ebro de la Cantabria de las fuentes clásicas y de la Antigüedad tardía ya ha sido aquí refrendada. ¿Con qué otra Cantabria podía, en el siglo XI, ser confundida? Con la Cantabria-ciudad a la que se refiere la teoría a la que se ha aludido más arriba.

Resulta pertinente rastrear la documentación que pueda informarnos acerca de la ciudad de Cantabria. En este sentido, pueden ser citados documentos como la dona-

33. El santo cura a una paralítica que llega al oratorio a finibus Amaiae abducta; hace lo mismo con una mujer coja de eodem territorio (VSE IX, 16; X, 17). Para el acercamiento a la figura de Emiliano como hombre santo y el trasfondo ideológico y social que su capitalización conlleva, vid. LÓPEZ CAMPUZANO, 1990; CASTELLANOS, 1994.

34. VSE XV, 22, [...] hic superuacua ne uideretur intexi eo quod nemo sit Cantabrorum qui hoc non aut uidere aut audire potuerit.

35. Las fuentes y comentarios para el período pre- y romano pueden ser consultados, entre otros, en los trabajos recogidos en SOLANA, 1991.

36. El repaso historiográfico a este asunto puede hallarse en VILLACAMPA, 1979.

37. La fuente básica para el conocimiento de estos sucesos es la Historia Wambae regis de Julián de Toledo, en la que se recoge la campaña de Wamba contra los vascones y la acampada del rey en territorio cántabro; por Calahorra y Huesca se dirige Wamba a sofocar la revuelta de Paulo (IUL. TOL., HW, 9-10).

38. [...] Cantabriae sita est In mons Iggeto Iuxta fons Iberi/Et Leovildo rex destruxit Iste rex hereticus fuit (ed. GONZÁLEZ ECHEGARAY, 1976: 62). 
ción del rey Alfonso el Batallador a Fortun Alvarez de Medina, otorgándole la Torre de Almudebar, en Calahorra, apareciendo la frase in illa populatione de Cántabria ${ }^{39}$. El documento se fecha en marzo de 1132. En una carta de arras dada a Estefanía por su marido, García el de Nájera, en mayo de 1040, se explica cum omnibus uillis Cantabriensis ${ }^{40}$. Entre los testigos de algunos documentos del siglo XI aparece un Fortunio Ossoyz, dominans Cantabria, y Fortunio Usuaz, cantabriensis ${ }^{41}$. En función de estos textos, y básicamente a partir de la donación de Alfonso el Batallador, es evidente que desde los siglos XI-XII, al menos, existe una populatione Cantabria en el actual Monte Cantabria ${ }^{42}$. De ahí la posible confusión medieval -e historiográfica- con la Cantabria del Biclarense y de la VSE.

Por su parte, la arqueología aporta las siguientes informaciones: en la campaña de excavaciones efectuada en el yacimiento de Monte Cantabria en el año 1977 se detectaron tres niveles: a) celtibérico; b) tardorromano, entre los siglos III-V; c) medieval, con estructuras datables en la segunda mitad del siglo XII. Destaquemos que apareció una moneda de Alfonso II (1161-1196), con las leyendas ANFOS REX en el anverso y ARAGÓN en el reverso ${ }^{43}$. Una breve revisión general bastante más reciente ha simplificado las fases del yacimiento en la celtibérica y otra medieval, cuyos niveles más antiguos se sitúan en el siglo XI. Se registran, además, cuatro monedas de plata de Alfonso I (1104-1134) ${ }^{44}$.

¿Qué conclusiones extraemos de toda la documentación acerca del problema de Cantabria en época visigoda? Desde luego, la Cantabria mencionada por Juan de Bíclaro, Isidoro, Braulio, Julián de Toledo, la Nota 39, no es la populatione del Monte Cantabria. Ni las fuentes escritas ni las arqueológicas apuntan hacia lo contrario, puesto que las referencias a la populatione Cantabria sita en el monte del mismo nombre, como hemos visto, son tardías, y sólo en el siglo XIV se afírma explícitamente que esa población se halla junto al Ebro y Logroño ${ }^{45}$. Se debe, pues, situar la población llamada en las fuentes medievales Cantabria, en el yacimiento de Monte Cantabria, al menos desde el siglo XI, momento en que comienza a documentarse, tanto diplomática como arqueológicamente. Pero no es ésta, evidentemente, la Cantabria de las fuentes visigodas ${ }^{46}$, pues éstas hacen pensar en un concepto regional. Aún así, alegamos por la ocupación tardoner figura de Monte Cantabria.

39. RODRÍGUEZ R. DE LAMA, 1992 (=1976): doc. 101, 171.

40. Idem, doc. 3, 33 .

41. RODRÍGUEZ R. DE LAMA, 1975: 105.

42. El propio editor de la Nota aduce un texto tardío, fechado en el año 1389, que reza in illa populatione de sub Logronio, quam dicunt Cantabria, cfr. GONZÁLEZ ECHEGARAY, 1976: 85.

43. PÉREZ ARRONDO, 1979: 65-90.

44. PÉREZ ARRONDO, 1990: 10-13.

45. Aunque en la donación de Alfonso el Batallador del año 1132 ya aparece la entidad de Cantabria como una populatione.

46. Recientemente se ha continuado defendiendo la ecuación entre ambas, cfr. LARRAÑAGA, K., "El pasaje del Pseudo-Fredegario sobre el dux Francio de Cantabria y otros indicios de naturaleza textual y onomástica sobre la presencia franca tardoantigua al sur de los Pirineos", AEArq, 66 (1993), 185, n. 36. 
Por lo que hace referencia a la identidad de los pervasores que, según Juan de Bíclaro, son aniquilados por Leovigildo, poco podemos decir. La historiografía ha barajado tres hipótesis principales. Estos invasores serían: 1) suevos ${ }^{47}$;2) los propios cántabros $^{48}$; 3) francos ${ }^{49}$. La primera hipótesis se fundamenta en la noticia según la cual el suevo Miro efectúa una campaña contra los roccones en 572 (Ioh. Abb. Bicl. a. 572). El problema se plantea al intentar localizar a este pueblo, muy probablemente situado en las montañas cántabro-astures ${ }^{50}$. En todo caso, extraña sobremanera que el Biclarense no mencione explícitamente a los suevos como los verdaderos pervas $o$ res, puesto que era un pueblo muy conocido por este cronista. Lo mismo sucede con los francos. Pese a la dificultad manifiesta que este asunto presenta, parece probable que en realidad Leovigildo se enfrentase básicamente con los poderes locales de la zona cántabra que bien podían estar representados en el senatus Cantabriae al que alude Braulio en la $V S E^{51}$.

Vistos los problemas derivados de la localización geográfica de la Cantabria ocupada por Leovigildo en 574, que grosso modo puede ser definida como la zona del Alto Ebro, conviene referirse a la intensidad de la ocupación por parte del estado toledano. Juan de Bíclaro afirma que provinciam in suam revocat dicionem. El término provincia probablemente mantiene aquí una semántica laxa, en el sentido de "zona", "región" 52 . De hecho, no tenemos constancia de que el propio Leovigildo definiera una provincia en el sentido administrativo del término, si bien la falta de documentación positiva no sentencia la negación. Ante la oscuridad de las fuentes, las posiciones historiográficas caminan en la incertidumbre; en todo caso, como hipótesis de trabajo, puede resultar pertinente pensar en la configuración temprana -en la misma época de Leovigildo- de una demarcación administrativa por puro interés práctico: pensamos fundamentalmente en los aspectos estratégicos y fiscales.

Mateu y Llopis cita la ocupación leovigildiana de Amaia, el paso por Potes (numismática), el precedente romano de Iuliobriga en la ruta hacia el mar, las cecas visigodas de Calahorra y Tarazona, una estela hallada en Iuliobriga con onomástica goda, el tesorillo visigodo de la Hermida, y concluye: "Leovigildo había constreñido la Cantabria por el este, remontando el Ebro a través del país de vascones; por el sur, desde Saldania, llegando los visigodos hasta los Picos de Europa"53.

47. TORRES LÓPEZ y otros, $1976(=1940), 101$

48. GONZÁLEZ ECHEGARAY, 1966: 231-232. En cierto modo también SÁNCHEZ-ALBORNOZ, 1986: 45-46, que los considera tiranos locales.

49. MANGAS, SOLANA, 1985, 111.

50. Las diversas aproximaciones al tema han sido recogidas por BESGA MARROQUíN, 1983: 20 ss; NOVO GÜISAN, 1992: 65.

51. Vid. infra.

52. DU CANGE, VI, 1954: 546.

53. MATEU Y LLOPIS, 1944: 224-225. 
Por su parte, González Echegaray piensa que, junto a la conquista de Amaia, se incendiaría la acrópolis de Monte Cildá ${ }^{54}$, próxima en el espacio; estima, en virtud de los hallazgos monetales y broches descritos por Mateu y Llopis, que la Liébana habría sido ocupada y que incluso se podría haber llegado al mar. Sin embargo, niega una aculturación propia de una intensa ocupación del territorio y, del mismo modo, duda de la estabilidad de la operación, en general ${ }^{55}$. Tengamos en cuenta que González Echegaray habla de la campaña de 574 como dirigida hacia la actual Comunidad Autónoma cántabra, en su opinión de situar en esta demarcación la Cantabria mencionada en las fuentes clásicas y tardoantiguas hasta la plena época altomedieval. Aunque coincide con González Echegaray en esta apreciación geográfica, A. Besga defiende la plena ocupación de Cantabria en 574 y niega que dicho proceso se ciñera a la parte meridional de la actual Comunidad Autónoma cántabra, norte de Burgos y occidente de La Rioja ${ }^{56}$.

Probablemente deba ser la arqueología quien defina correctamente el tipo de asentamientos practicados durante el siglo VI en la actual Comunidad Autónoma de Cantabria, y, de igual manera, en la de La Rioja y en la provincia de Burgos, esto es, en el Alto Ebro en sentido global. Desde el punto de vista de la Historia Antigua poco puede decirse: el monarca Leovigildo lleva a cabo una expedición contra el enclave de Amaia, sometiendo la zona (prouincia) a su dominio; sabemos, además, que en este ámbito existía una "asamblea", puesto que la VSE (XXVI, 33) alude claramente a un senatus eius, refiriéndose el pronombre demostrativo a Cantabria. Una asamblea en la que recae, según Braulio, la responsabilidad del ataque leovigildiano, y formada probablemente por miembros de la aristocracia dominante en el Alto Ebro ${ }^{57}$. La Galia del siglo VI descrita por Gregorio de Tours presenta igualmente grupos de poder aristocráticos que el Turonense identifica como senatores, término que conjuga toda una evolución histórica a nivel social y que, desde luego, no se refiere -salvo casos muy concretos- a descendientes directos de miembros del senado imperial, sino que más bien adquiere un sentido más amplio en alusión genérica a los grandes propietarios $^{58}$. Junto a esta independencia de los poderosos locales, Leovigildo se halla-

54. Las excavaciones arqueológicas en Monte Cildá han revelado un hábitat desde el siglo I a. C., ocupación durante el período altoimperial, muralla datable en el siglo III, reforzada en el V: "La vida de esta muralla iniciada en el siglo $\mathrm{V}$ debió de ser larga, utilizándose posiblemente como reducto defensivo ante el temor de una conquista visigoda la cual debió de hacerse realidad con Leovigildo, que sabemos conquistó Cantabria en el año 574. En este año Cildá debió de pasar a dominio visigodo, como nos lo prueban algunos hallazgos cerámicos y de armas que pueden ser, cronológica y tipológicamente, incluidos en esta época", cfr. GARCÍA GUINEA, M. A., GONZÁLEZ ECHEGARAY, J., SAN MIGUEL RUIZ, J. A., 1966: 68. Sitúan estos autores en este yacimiento la Vellica conocida por los itinerarios (idem, 23).

55. GONZÁLEZ ECHEGARAY, 1966: 233.

56. BESGA MARROQUÍN, 1983: 23-26.

57. Resulta complicado ir mucho más allá de lo que la fuente dice (reunión de poderosos locales) para encontrar en este senatus un residuo de la organización tribal cántabra, cfr. NELSON, 1970: 185, n. 42. Es probable, incluso, que estemos ante una erudición del propio Braulio, cfr. SÁNCHEZ-ALBORNOZ, 1971: 107).

58 Para las referencias de Gregorio de Tours a los senatores galos durante el siglo VI, cfr. GILLIARD, 1979. 
ría incentivado a eliminar a unos invasores hoy aún oscuros para nosotros. En cualquier caso, las fuentes no permiten asegurar ni negar la ocupación visigoda de la fachada septentrional cántabra, ni tampoco medir el grado de intensidad del control del Alto Ebro por parte del estado toledano.

Unos siete años después de la campaña contra Cantabria, Leovigildo ocupa parte de Vasconia y funda una nueva ciudad, Victoriaco ${ }^{59}$. Más allá de la situación concreta de Victoriaco ${ }^{60}$, es interesante comprobar la confrontación entre el estado visigodo y los vascones ${ }^{61}$, asunto éste que se convierte en un denominador común durante el siglo VII. La desaparición de las redes estatales del imperio romano en Occidente pudo influir en la progresiva debilidad de los mecanismos de intercambio; frente a éstos, las razzias y las rapiñas se convertían en alternativas eficaces para una sociedad como la vascona, estructuralmente distinta a los grupos inmediatamente meridionales.

En definitiva, los siglos V-VI presentan la progresiva inclusión del Alto Valle del Ebro en la órbita del estado visigodo, si bien existen algunas variantes que enriquecen la problemática histórica. Los grupos aristocráticos siguen documentándose en todo el período, y del mismo modo los sectores dependientes, que forman parte indispensable de los esquemas de explotación de los recursos. Frente a la presión del estado romano primero y del visigodo después, surgen fuerzas centrífugas como la propia aristocracia local o los movimientos armados vascones, a los que tendrá que hacer frente el gobierno de Toledo; el trasunto evenemencial de estos esquemas estructurales viene definido por las campañas de Leovigildo de 574 y 581 . La creación de la provincia de Cantabria con un $d u x$ al frente es un hecho únicamente documentado a partir del siglo VII, excediendo por ello los límites temporales de este trabajo ${ }^{62}$. En realidad, el siglo VII presenta una variedad de problemas (el ducado de Cantabria, las campañas contra los vascones, las relaciones con los poderes francos) que merecerán un estudio pormenorizado en otro momento.

59. IOH. ABB. BICL., a. 581a. 581, Leovegildus rex partem Vasconiae occupat et civitatem, que Victoriacum nuncupatur, condidit; MILES, 1952: 85, 18. A este respecto, BESGA MARROQUÍN, 1983: 2326, estima que la toma de Cantabria del 574 responde también al antiguo solar cántabro, y que la campaña de 581 contra los vascones no supuso la conquista de éstos. THOMPSON, 1990: 86, piensa que, como mínimo, ocupó parte de Vasconia. En realidad, la respuesta a estas disquisiciones la proporciona el propio Juan de Bíclaro, quien explícitamente indica que se ocupó parte de Vasconia.

60. En torno a la actual Vitoria, o bien sobre la vieja Veleia. La mayoría de los autores están de acuerdo en situar Veleia en las ruinas de Iruña, unos kilómetros al oeste de Vitoria (a modo global puede verse NIETO, 1958; algunas opiniones más recientes han sido recogidas en NOVO GÜISAN, 1992: 135-137). Sin embargo, no está clara la conexión entre este yacimiento y la posterior Victoriaco; podría el visigodo aprovechar las ruinas de Veleia para fundar sobre ella Victoriaco, pero también podría haber llevado ésta a otro sitio, como el solar de la actual Vitoria (cfr. BOSCH-GIMPERA, 1944: 293; NOVO GÜISAN, 1992: 155). Poco más se puede decir sin caer en la especulación, y así lo reconoce AZKARATE, 1988: 496.

61. Por estas mismas fechas, los vascones al norte de los Pirineos vencen a los ejércitos de Bladastes, general de Chilperico I de Neustria (GREG. TUR. HF, VI, 12; FREDEG., III, 87). En los últimos años del siglo, será Recaredo quien se enfrente a los vascones (ISID., $H G, 54$ )

62. Aunque ya hemos apuntado la hipótesis de una probable demarcación administrativa inmediatamente posterior a la campaña de 574 , en función de unos intereses eminentemente prácticos. 


\section{BIBLIOGRAFÍA}

ABADAL, R. D. 1960

Del Reino de Tolosa al Reino de Toledo, Madrid.

ABASOLO, J. A., 1978

Carta Arqueológica de la provincia de Burgos. Partidos judiciales de Castrojeriz y Villadiego, Burgos.

ALBERTINI, E. 1923

Les divisions administratives de l'Espagne romaine, Paris.

ARCE, J. 1980

"La 'Notitia Dignitatum' et l'armée romaine dans la diocesis Hispaniarum": Chiron, 10, 593-608.

ID. 1986

El último siglo de la España romana: 284-409, Madrid.

ID. 1988

España entre el mundo antiguo y el mundo medieval, Madrid.

AZKARATE, A. 1988

Arqueología cristiana de la Antigüedad Tardía en Alava, Guipúzcoa y Vizcaya, Vitoria.

BARBERO, A., VIGIL, M. 1974

Sobre los orígenes sociales de la Reconquista, Barcelona.

BARRAL I ALTET, X. 1976

La circulation des monnaies suèves et visigotiques. Contribution à l'histoire économmique du royaume visigot, München.

BESGA MARROQUÍN, A. 1983

La situación política de los pueblos del norte de España en la época visigoda, Bilbao.

BOSCH-GIMPERA, P. 1944

El poblamiento antiguo y la formación de los pueblos de España, México.

BRAVO, G. 1983

"Las revueltas campesinas del Alto Valle del Ebro a mediados del siglo V d. C. y su relación con otros conflictos sociales contemporáneos (Una revisión sobre bagaudas)": I Col. Hist. La Rioja, Cuadernos de Investigación, Historia, IX, 1, Logroño, 219-230. 
APROXIMACIÓN A LA HISTORIA POLÍTICA DEL ALTO VALLE DEL EBRO DURANTE LOS S. V-VI D.C.

ID. 1985

"La bagauda hispana y la identidad de los possessores de la Tarraconense (puntualizaciones sobre la teoría social)": II Col. Hist. La Rioja, Logroño, 197-209.

BRÖ̈NS, M. 1955-56

"Los Francos en el poblamiento de la Península Ibérica durante los siglos VI y VII": Ampurias, XVII-XVIII, 59-77.

CABALLERO ZOREDA, L. 1984

"Arqueología tardorromana y visigoda en la provincia de Soria": I Symposium de arqueología soriana, Soria, 433-458.

CASTELLANOS, S. M. 1994

"La capitalización episcopal del culto de los santos y su trasfondo social: Braulio de Zaragoza": SHHA, XII 169-177.

ID. 1995

"La implantación eclesiástica en el Alto Ebro durante el siglo VI d. C.: la 'Vita Sancti Aemiliani"": HAnt, XIX (En prensa).

CLEMENTE, G. 1968.

La 'Notitia Dignitatum', Cagliari.

COLLINS, R. 1980

"Mérida and Toledo: 550-585": Visigothic Spain: new approaches, ed. James, E., Oxford, 189-219.

ID. 1986

España en la Alta Edad Media, 400-1000, Barcelona.

DEMOUGEOT, E. 1956

"Une lettre de 1'empereur Honorius sur 1'hospitium des soldats": Rev. Hist. de Droit Français et Étranger, 34, 25-49.

DIEGO SANTOS, F., 1959

Epigrafía romana de Asturias, Oviedo.

DOMÍNGUEZ MONEDERO, A. 1986A

"Las necrópolis visigodas y el carácter del asentamiento visigótico en la Península Ibérica": Actas del I Congreso de Arqueología Medieval Española, II, Visigodo, Zaragoza, 165-186.

ID. $1986 \mathrm{~B}$

"La 'Chronica Caesaraugustana' y la presunta penetración popular visigoda en Hispania": Ant. y Crist., III, 61-68. 
DOPSCH, A. 1948

"Las instituciones agrarias de los reinos germánicos desde la centuria quinta a la novena": Historia económica de Europa desde la decadencia del imperio romano, I, Madrid, 205-235.

DU CANGE, 1954.

Glossarium mediae et infimae latinitatis, Graz.

ESCRIBANO, Mª . V. 1984

"La iglesia calagurritana entre ca. 457 y 465 . El caso del obispo Silvano": Calahorra, bimilenario de su fundación. Actas del I Symposium de historia de Calahorra, Madrid, 265-272.

ESPINOSA, U. 1991

"El siglo V en el Valle del Ebro: arqueología e historia": Ant. y Crist., VIII, 275-288.

FERNÁNDEZ ARDANAZ, S. 1992

"La diffusione del cristianesimo nel nord-ovest della Penisola Iberica: aspetti sociali ed antropoligici": XXXIX Corso di cultura sull'arte ravennate e bizantina, Ravenna, 297-358.

ID. 1994

"Cristianizzazione e cambiamenti sociali nelle culture montane del Nord dell'Hispania": Cristianesimo e Specificità Regionali nel Mediterraneo Latino (sec. IV-VI), XXII Incontro di studiosi dell'antichità cristiana, Roma, 6-8 maggio 1993, Roma, 483-512.

GARCÍA GALLO, A. 1940-41

"Notas sobre el reparto de tierras entre visigodos y romanos": Hispania, I, 40-63.

GARCÍA GUINEA, M. A., GONZÁLEZ ECHEGARAY, J., SAN MIGUEL RUIZ, J. A. 1966

"Excavaciones en Monte Cildá. Olleros de Pisuerga (Palencia). Campañas de 196365": Excavaciones arqueológicas en España, 61.

GARCÍA IGLESIAS, L. 1975

"El intermedio ostrogodo en Hispania (507-549 D. C.)": HAnt, V, 89-120.

GARCÍA MERINO, C. 1975

Población y poblamiento en Hispania romana. El conventus cluniensis, Valladolid.

GARCÍA MORENO, L. A. 1974

"Estudios sobre la organización administrativa del reino visigodo de Toledo", $A H D E$, XLIV, 5-155.

ID. 1987

"La arqueología y la historia militar de los visigodos en la Península Ibérica": II Congreso de Arquología Medieval Española, II, Madrid, 331-336. 
APROXIMACIÓN A LA HISTORIA POLÍTICA DEL ALTO VALLE DEL EBRO DURANTE LOS S. V-VI D_C.

GILLIARD, F. D. 1979

"The Senators of Sixth-Century Gaul": Speculum, 54, 685-697.

GOFFART, W. 1980

Barbarians and Romans, A. D. 418-584. The techniques of accomodation, Princeton.

GONZÁleZ BLANCO, A., ESPINOSA RUIZ, U., SÁENZ GONZÁLEZ, J. M. 1979

“La población de la Rioja durante los siglos obscuros": Berceo, 96, 81-105.

GONZÁLEZ ECHEGARAY, J. 1966

Los Cántabros, Madrid.

ID. 1976

"La 'Nota de Cantabria' del códice emilianense 39 y las citas medievales de Cantabria": Altamira, XL, 61-94.

JONES, A. H. M. 1986

The Later Roman Empire 284-602, I, Oxford.

LARRAÑNGA, K. 1989

"En torno al caso del obispo Silvano de Calagurris: consideraciones sobre el estado de la iglesia del alto y medio Ebro a fines del imperio": Veleia, 6, 171-191.

ID. 1993

"El pasaje del Pseudo-Fredegario sobre el dux Francio de Cantabria y otros indicios de naturaleza textual y onomástica sobre la presencia franca tardoantigua al sur de los Pirineos": AEArq, 66, 177-206.

LÓPEZ CAMPUZANO, M. 1990

“Obispo, comunidad y organización social: el caso de la Vita Emiliani": Ant. y Crist., VII, 519-530.

MANGAS, J., SOLANA, J. Mª 1985

Historia de Castilla y León, 2, Romanización y germanización de la Meseta Norte, Valladolid.

MATEU Y LLOPIS, F. 1944

"Sobre los límites de la conquista visigoda en Vasconia y Cantabria": Ampurias, VI, 222-225.

MATTHEWS, J. 1975

Western Aristocracies and Imperial Court, A. D. 364-425, Oxford.

MILES, G. C., 1952

The coinage of the Visigoths of Spain: Leowigild to Achila II, New York. 
MONREAL JIMENO, L. A. 1989

Eremitorios rupestres altomedievales (el Alto Valle del Ebro), Bilbao.

MOORHEAD, J. 1992

Theoderic in Italy, Oxford.

MUSSET, L. 1982

Las invasiones. Las oleadas germánicas, Barcelona.

NELSON, C. A. S. 1970

Regionalism in Visigothic Spain, University of Kansas.

NIETO, G., 1958

El oppidum de Iruña (Alava), Vitoria.

NOVO GÜISAN, J. M. 1992

Los pueblos vasco-cantábricos y galaicos en la Antigüedad Tardía. Siglos III-IX, Alcalá de Henares.

ORLANDIS, J. 1962

"E1 poder real y la sucesión al trono en la monarquía visigoda": Estudios Visigodos, III, Roma-Madrid.

PALOL, P. DE. 1966

"Demografía y arqueología hispánicas de los siglos IV al VIII. Ensayo de cartografía": BSAA, XXXII, 5-66.

PARADISI, B. 1978

"La caduta dell'impero romano e la crisi de la civiltà in Occidente": VV.AA., La fine dell'impero romano d'Occidente, Roma, 49-67.

PÉREZ ARRONDO, C. L. 1979

"Excavaciones arqueológicas en Monte Cantabria. 1977. Informe preliminar":

Cuadernos de Investigación, V, 65-90.

ID. 1990

"El yacimiento arqueológico de Monte Cantabria (Logroño)": Estrato, 2, 10-13.

REINHART, W. 1945

"Sobre el asentamiento de los visigodos en la Península", AEArq, XVIII, 124-139.

REMONDON, R. 1984

La crisis del Imperio Romano de Marco Aurelio a Anastasio, Barcelona.

RODRÍGUEZ R. DE LAMA, I. 1975

"La tenencia de Meltria en el siglo XI": Berceo, XXIX, 105-108. 
ID. $1992(=1976)$

Colección Diplomática Medieval de La Rioja, T.II, Documentos (923-1168), Logroño.

ROUSSEAU, P. 1992

"Visigothic Migration and Settlement, 376-418: some excluded hypotheses": Historia, XLI, 3, 345-361.

SÁNCHEZ-ALBORNOZ, C. 1971

"Ruina y extinción del municipio romano en España e instituciones que le reemplazan":Estudios Visigodos, Roma, 1971

ID.1979

Estudios Polémicos, Madrid.

ID. 1986

Orígenes de la nación española. El Reino de Asturias, Madrid.

SÁNZ, R. 1986

"Aproximación al estudio de los ejércitos privados en Hispania durante la antigüedad tardía": Gerión 4, 225-264.

SCHÄFERDIEK, K.,

Die Kirche in den Reichen der Westgoten und Suewen bis zur Errichtung der westgotischen katholischen Staatskirche, Berlin.

SIVAN, H. S. 1985

"An unedited letter of the emperor Honorius to the spanish soldiers": Zeitschrift für Papyrologie und Epigraphie, 61, 273-287.

SOLANA, J. Ma 1978

Autrigonia romana. Zona de contacto Castilla-Vasconia, Valladolid.

ID (ED.). 1991

Las entidades étnicas de la Meseta Norte de Hispania en época prerromana, Valladolid.

STEVENS, C. E. 1957

"Marcus, Gratian, Constantine": Athenaeum, XXXV, 3-4, 316-347.

STROHEKER, K. F. 1965

"Spanische Senatoren der spätromischen und westgotischen Zeit": Germanentum und Spätantike, Zürich-Stuttgart, 54-87.

THOMPSON, E. A. 1978

"The End of Roman Spain": NMS XII, 3-22. 
ID. 1981

"Revueltas campesinas en la Galia e Hispania tardorromanas": Estudios sobre Historia Antigua, ed. Finley, M. I., Madrid, 333-348.

ID. 1990

Los godos en España, Madrid.

TORRES LÓPEZ, M. Y OTROS. 1976 (=1940)

España Visigoda (414-711 de J. C.), HEMP, III, Madrid.

TOVAR, A. 1989

Iberische Landeskunde, II, 3, Tarraconensis, Baden-Baden.

VILLACAMPA, Mª . A. 1979

"Historiografía de 'Monte Cantabria": Cuadernos de Investigación, V, 41-50.

WOLFRAM, H. 1990

History of the Goths, Berkeley-Los Angeles.

ZECCHINI, G. 1983

Aezio: l'ultima difesa dell'occidente romano, Roma. 